\title{
An axillary port with concealed scar for liposuction of gynaecomastia
}

Sir,

In liposuction for gynaecomastia through access ports in central locations such as periareolar, ${ }^{[1]}$ intra-areolar ${ }^{[1]}$ and transnipple ${ }^{[2]}$ areas, suction of subareolar tissue is difficult because of its proximity to the port..$^{[3]}$ For this reason, additional access incisions remote from nipple areolar complex have been recommended. One of the common sites for a remote port is the anterior axillary fold ${ }^{[1,4]}$ where the scar becomes visible revealing the evidence of past surgery, causing embarrassment to the patient.

Conventionally, during liposuction of gynaecomastia, with the patient in the supine position, the arm is kept either fully adducted making it lie by the side of the chest on the operating table or abducted by $90^{\circ}$ making it lie on the arm splint. Both these positions place the anterior chest wall and the axilla at two different planes making them meet each other at $90^{\circ}-120^{\circ}$ angle at the anterior axillary fold formed by pectoralis major muscle, which poses an obstruction to passage of the liposuction cannula from axilla, whether from the hair-bearing area or from the area behind the anterior axillary fold, to breast; any attempt to reach the anterior chest wall can direct the cannula deep into the axilla, causing damage to the axillary lymph nodes and lymphatics. Due to this, in order to get adequate access to the breast, the so-called axillary port is created on the anterior axillary fold, a site where the scar becomes visible. In our technique, the incision for the port is made on the crease over the anteroinferior aspect of the hair-bearing skin of the axilla. With the patient in the supine position, the arm is kept fully abducted, keeping it by the side of the head, which pushes the scapula, and thus the axilla, forward [Figure 1]. The forward push of the axilla brings it into the same plane as anterior chest wall. In this position, the cannula can access all the areas of breast from the port in the lower hair-bearing area of the axilla [Figure 2]. The scar of 


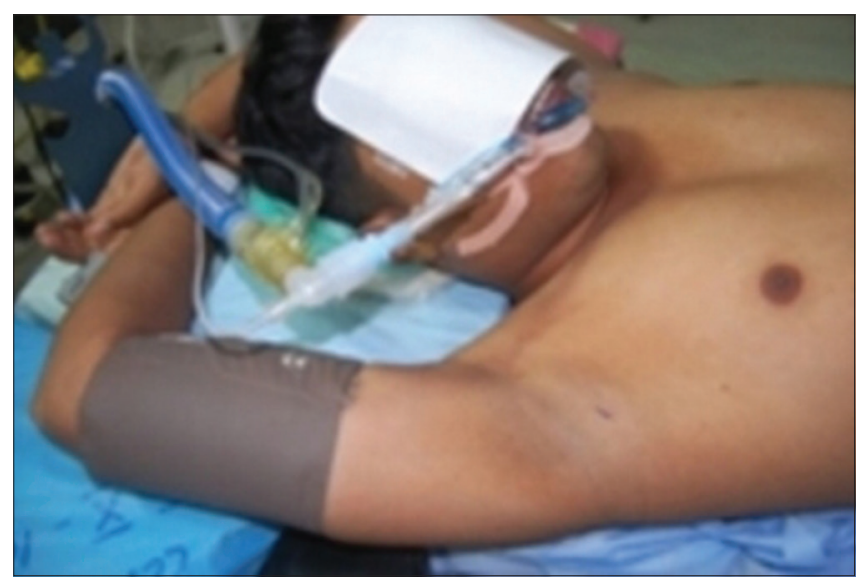

Figure 1: Case of Simon's Grade Ila gynaecomastia. Intraoperative view showing positioning of the right arm and marking of the axillary port within hair-bearing area

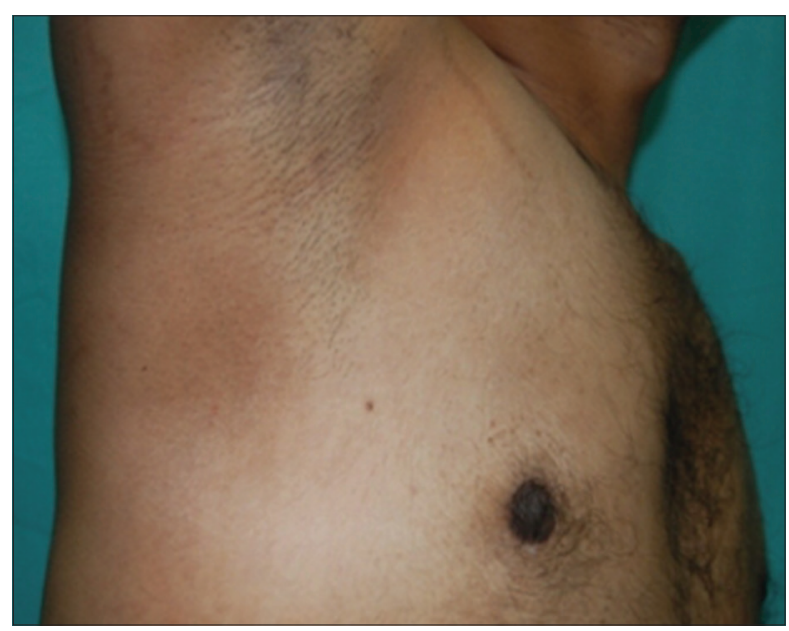

Figure 3: Same case: Imperceptible scar in the 6-month follow-up view of the right axilla

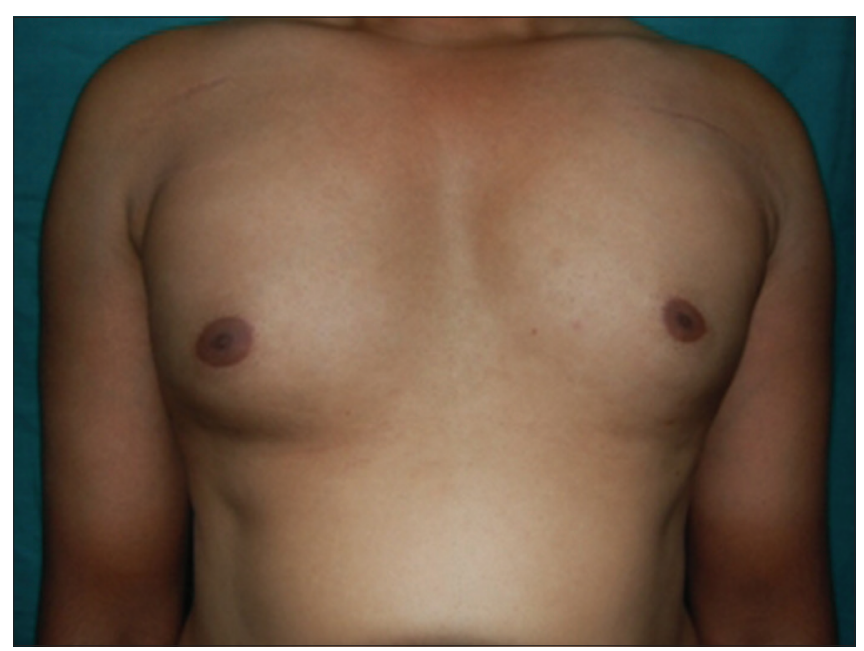

Figure 5: Same case: Pre-operative front view of the chest

this port remains concealed under the cover of the hair [Figures 3 and 4]. During surgery, care should be taken to prevent stretching the shoulder away from

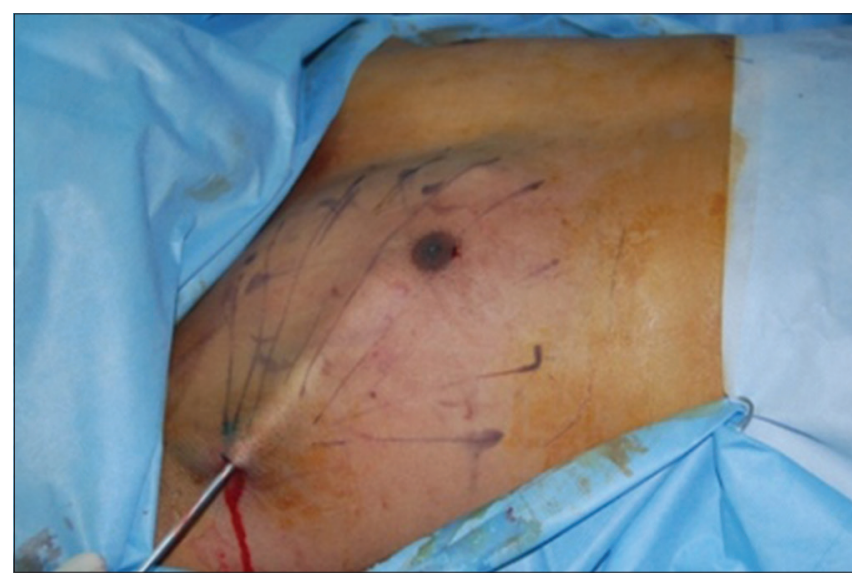

Figure 2: Same case: Intraoperative view showing liposuction through the right axillary port

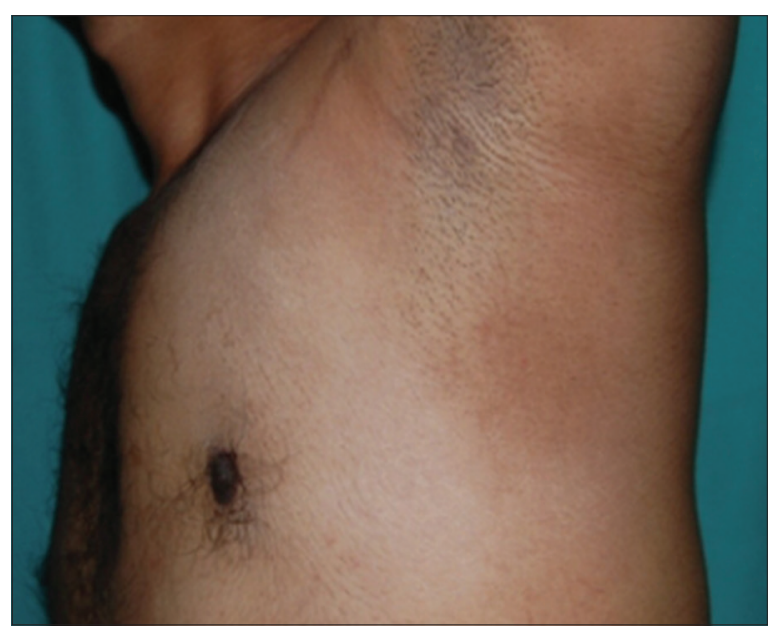

Figure 4: Same case: Imperceptible scar in 6-month follow-up view of the left axilla

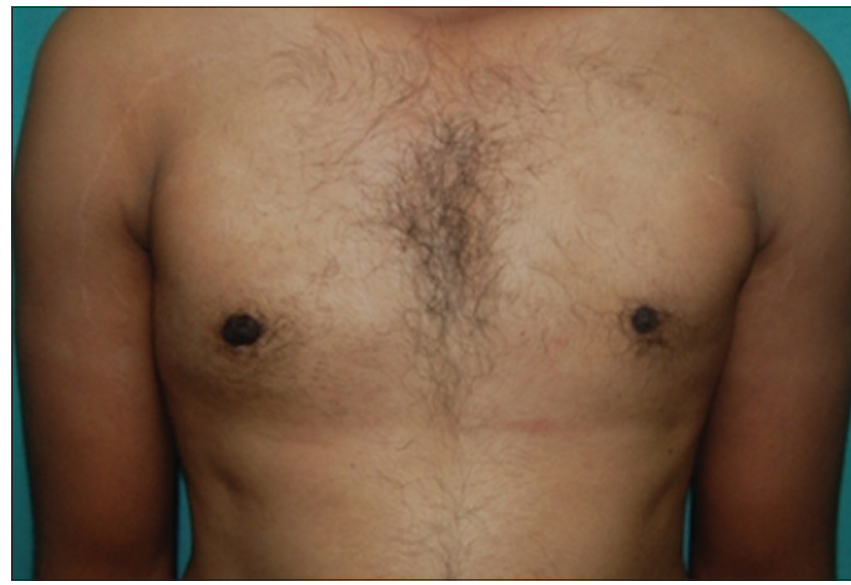

Figure 6: Same case: 6-month follow-up front view of the chest

the neck by keeping the arm by the side of the head and also, restricting the full abduction of the arm to the duration of liposuction through the axillary port only to protect the brachial plexus from possible trauma. A concealed scar hides the evidence of past 
surgery, and hence provides greater satisfaction to the patient [Figures 5 and 6] than a visible scar. The positioning of the arm in fully abducted position is the innovative step that helps in successfully using the hair-bearing area as the site of the port.

\section{Acknowledgement}

We are thankful to the Dean, Mahatma Gandhi Medical College and Research Institute, and the Medical Superintendent, MGMCRI Hospital, for permitting us to use the institutional facilities.

\section{Financial support and sponsorship}

Nil.

\section{Conflicts of interest}

There are no conflicts of interest.

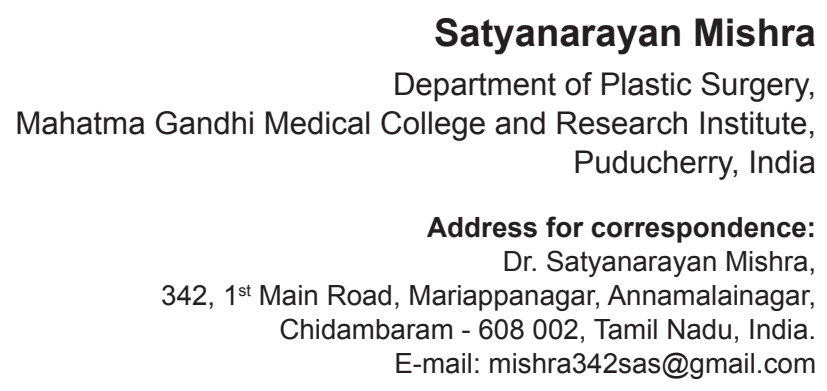

\section{REFERENCES}

1. Malata C, Lau C, Kumiponjera D. Gynecomastia: An algorithmic approach to surgical management (with special emphasis on liposuction). In: Stone C, editor. The Evidence of Plastic Surgery-Google Book. TFM Publish Ltd, Shrewsbury, UK; 2008. 273-85.

2. Mishra RK. Trans-nipple removal of fibro-glandular tissue in gynaecomastia surgery without additional scars: An innovative approach. Indian J Plast Surg 2014;47:50-5.

3. Murali $B$, Vijayaraghavan $S$, Kishore $P$, lyer $S$, Jimmy $M$, Sharma $\mathrm{M}$, et al. Cross-chest liposuction in gynaecomastia. Indian J Plast Surg 2011;44:81-6.

4. Abramo AC. Axillary approach for gynecomastia liposuction. Aesthetic Plast Surg 1994;18:265-8.

This is an open access article distributed under the terms of the Creative Commons Attribution-NonCommercial-ShareAlike 3.0 License, which allows others to remix, tweak, and build upon the work non-commercially, as long as the author is credited and the new creations are licensed under the identical terms.

\begin{tabular}{|l|l|}
\hline \multicolumn{2}{|c|}{ Access this article online } \\
\hline Quick Response Code: & Website: \\
\hline
\end{tabular}

How to cite this article: Mishra S. An axillary port with concealed scar for liposuction of gynaecomastia. Indian J Plast Surg $2017 ; 50: 221-3$

๔ 2017 Indian Journal of Plastic Surgery | Published by Wolters Kluwer - Medknow 